\title{
A Systematic Review of Effectiveness of Automated External Defibrillators Delivered by Drones
}

\author{
Tomoya Shirane ${ }^{1}$ \\ ${ }^{1}$ School of Graduate Studies, Open University of Japan, Chiba, Japan \\ Correspondence: Tomoya Shirane, School of Graduate Studies, Open University of Japan, Chiba, Japan. Tel: \\ 81-43-276-5111. E-mail: tomoya.shirane@gmail.com
}

Received: August 30, 2020 Accepted: October 9, 2020 Online Published: October 23, 2020

doi:10.5539/gjhs.v12n12p101 URL: https://doi.org/10.5539/gjhs.v12n12p101

\begin{abstract}
Background: According to the 2019 annual report by Fire and Disaster Management Agency (FDMA) in Japan, the survival rate of patients with Out-of-Hospital cardiac arrest (OHCA) who were rescued by Automated External Defibrillators (AED) was 6.2 times higher than those who were not treated appropriately. Unmanned Aerial Vehicles (UAV) have been evaluated as the means of delivering medical equipment and goods. This study was therefore designed to evaluate the effectiveness of UAV technology applied to AED delivery through a systematic review methodology.
\end{abstract}

Methods: Preferred Reporting Items for Systematic Reviews and Meta- Analyses (PRISMA) statement was utilized to guide the review. Electronic databases such as Medline through PubMed and CiNii were searched. Search terms were used in a variety of combinations, including AED, UAV, and drone in English and Japanese.

Results: Nine articles were identified through the review process. Most of the studies were conducted in Western countries, and all of them were done after 2016. Seven studies evaluated the time reductions in the delivery of the defibrillation in OHCAs by simulation study methods and/or test flights of UAV. All the studies showed the positive results regarding the time reductions to AED access by bystanders compared with the current setting of no UAV networks.

Conclusion: The studies included in this review showed UAV technology around AED delivery would have the potential to reduce the time of the defibrillation in OHCA patients. More evidence especially around the real-world utilization and the cost-effectiveness of the technology deployment are expected for the future adaptation.

Keywords: AED, Automated External Defibrillator, UAV, unmanned aerial vehicle, drone, cardiac arrest

\section{Introduction}

According to the annual report of 2019 by Fire and Disaster Management Agency (FDMA) from the Ministry of Internal Affairs and Communications (MIC) in Japan, one-month survival rate of patients with the cardiogenic cardiopulmonary dysfunction outside of hospitals, also known as Out-of-Hospital Cardiac Arrest (OHCA), mainly due to the ventricular fibrillation (VF), was reported as 55.9\% when they were taken care of by Automated External Defibrillators (AED) by people who were around the event areas (bystanders). The survival rate of OHCA was about 6.2 times higher than that without their urgent cares (Fire and Disaster Management Agency, 2019). The early interventions by bystanders using AED and the delivery of the electrical shock are critically important to save lives of OHCA victims, and it is well recognized through the evidence from the published researches that the survival rate may decrease by $7 \%$ to $10 \%$ for each 1 minute delay of the defibrillation (American Heart Association, 2000). However, according to the white papers of FDMA, the number of OHCA patients in 2018 was 25,756, while the number of the defibrillation by AED was 1,254, which resulted in only $4.9 \%$ of the total cases (Fire and Disaster Management Agency, 2019).

On the other hand, as our technologies advance, Unmanned Aerial Vehicles (UAV), also known as drones, are being used for medical applications. For example, John Hopkins University has a program to utilize UAV to transport the organs (Ramachandra, 2016). Momont at the Delft University of Technology in the Netherlands also developed the Ambulance Drone and demonstrated the possibility of AED transport by UAV technology (Grieco, 2015).

In Japan UAV technology is considered as one of the solutions for the low rate of AED usage in the future. A 
newspaper article broadcasted the first large-scale demonstration experiment in Shizuoka Prefecture. This study was conducted in 2018, jointly with Japan AED Foundation. The experiment demonstrated that UAV could deliver AED to the twice a longer distance by the same time duration (Tanaka, 2018).

The expectations for the actual use of AED transportation technology by UAV are increasing. However, it is still unclear how the technology can be effective in AED delivery such as the potential of reducing the time until the first shock by bystanders. Therefore, the purpose of this study is to explore the literatures that have already been published in the public about UAV for AED delivery and evaluate the potential effectiveness of the implementation of this new technology.

It is noted at the beginning of this paper that the terms of UAV and drones are used as convertible, as there are studies included in this review using the term of drone to mean UAV.

\section{Methods}

This systematic review design was registered prospectively in the PROSPERO database, International prospective register of systematic reviews by Centre for Review and Dissemination, University of York (National Institute for Health Research, n.d.), as the registration number of CRD42020167599 (Shirane, 2020). The entire design is available elsewhere, but the details are described in the following sections.

\subsection{Search Strategy}

This review was performed along with the guidelines of Preferred Reporting Items for Systematic Reviews and Meta-Analyses (PRISMA) statement (Moher, Liberati, Tetzlaff, Altman, \& Group, 2009). The databases that the literature search was done were MDLINE through PubMed and CiNii, Citation Information by National Institute of Informatics (National Institute of Informatics, 2018). The languages that were considered as the inclusion criteria were English and Japanese. English articles were looked for through PubMed, and Japanese articles were from CiNii. The search terms used in this review were the combinations of AED or Automated External Defibrillator and UAV, Unmanned Aerial Vehicle, or drone. All these search terms were looked for in Title and Abstract in PubMed in English. Also, these terms were used for CiNii in Japanese as the free word search.

\subsection{Screening}

The screening steps for the review were developed along with PRISMA Diagram (Moher et al., 2009). After identifying and excluding the duplicated articles, the titles and abstracts retrieved from the databases were read through as the screening review. After the first screening, the reasons for inclusion and exclusion were documented in the study data collection file. Then, the full text review was done for the remaining articles to identify the studies to be included into the review.

\subsection{Eligibility}

The overview of the eligibility criteria is described in Table 1 . The literature search was initiated and completed between May11, 2020 and July18, 2020. Articles were eventually included in this review if they were published between January 01, 2014 and July 18, 2020. The year 2014 as a cutoff was determined because AED delivered by UAV technology was first introduced as so-called Ambulance Drone by Momont from Delft University of Technology (Grieco, 2015). This review was, in other words, designed to include the published studies and articles after this technology was well recognized by the contribution by Momont. Again, the languages were restricted only in English and Japanese.

Table 1. Inclusion and exclusion criteria for identifying relevant studies via search strategy

\begin{tabular}{ll}
\hline Inclusion Criteria & Exclusion Criteria \\
\hline Studies involving UAV technology in AED delivery & $\begin{array}{l}\text { Studies not about the combination of UAV delivery } \\
\text { technology and AED }\end{array}$ \\
Published in either language of English or Japanese & Not studies such as Opinion, Editorial, Review, and so on \\
Published in or after the date of January 01, 2014 & \\
\hline
\end{tabular}

\subsection{Data Extraction and Analysis}

General and major information was extracted from the studies finally included into the review, such as the locations like countries and regions, study design and methodology, sample sizes, results, and major findings. These kinds of information were captured thoroughly and described in a table format so that they could be compared and analyzed qualitatively. 


\section{Results}

The literature search identified 6,368 studies after excluding the duplicated articles out of 6,376. As the output from the first screening of these articles, 30 articles were under the full text review. After the full text review on 30 potentially relevant studies, 9 articles fell into the included studies by meeting all the criteria. The whole process of the literature search and final identification were described in Figure 1, along with PRISMA flow diagram (Moher et al., 2009).

\subsection{General Characteristics}

Table 2 provides the summary of the studies included in this review. Most of them employed simulation methods to analyze the effectiveness of UAV deployment with AED delivery in certain regions. These papers were published between 2016 and 2020. Three originated in Sweden, two from the United States and Canada, one each from the United Kingdom and Japan.

This review limited the publication in or after the year of 2014, and Table 3 described the distribution of the publication year of the studies included in this review. It can be observed that out of almost 6 and half years of the searched period, the last one and half years covered more than half articles.

\subsection{Estimated Reductions in Time to Defibrillation in OHCAs by Simulation Models}

Most of the included studies in this review, 7 out of 9, showed the estimated outcomes about the potential reductions until the defibrillation in OHCAs by AED delivered by UAV. 5 studies were conducted as the simulation models using different regions with their historical data in European and Northern American countries, such as Sweden, the United Kingdom, Canada, and the United Sates.

Claesson et al. employed a Geographic Information System (GIS) by combining the data from the Global Positioning System (GPS) and historical OHCA in Stockholm, Sweden to find suitable placements and visualize response times for the use of an AED equipped drone. 20 suitable locations covering 3,165 cases were identified and selected in the study. Two different geographical models, urban and rural, were calculated using a multi-criteria evaluation (MCE) model, and the drone arrived before Emergency Medical Services (EMS) in $32 \%$ of cases with a mean amount of 1.5 minutes saved for the urban model. In rural OHCA, the drone arrived before EMS in $93 \%$ of cases with a mean amount of time saved of $19 \min$ (Claesson et al., 2016). Mackle et al. conducted a simulation study by utilizing several databases to estimate the optimal number of drone bases in 5 Health and Social Trust Care areas in Northern Ireland, the United Kingdom. A synthetic dataset generated by the author of probabilistic geolocations of 10,000 OHCA incidents was included. The study resulted in 78 drone bases in total, and the average response time after the drone network implemented was reduced in all the trust areas. Actually, the time was slightly reduced in Belfast, but the author observed this was due to a larger population density in a smaller area with a greater number of emergency resources already available. The other trust areas were more rural with a greater distance from an ambulance station or AED, and so these trust areas have seen approximately a $50 \%$ improvement in response times after implementing a drone network (Mackle et al., 2020).

From Canada, Boutilier et al. conducted simulation models with two stages. The first stage used an optimization model to determine the minimum number and location of drone bases required to improve the historical median response time by one, two, or three minutes in Southern Ontario. Once the base locations were determined, the second stage used a queuing model to determine the number of drones to be stationed at each base. Out of Rescu Epistry cardiac arrest dataset from Tronto Regional RescuNET from 2006 through 2014, 53,702 OHCAs were extracted. In the most urban region, the 90th percentile of the AED arrival time was reduced by 6 minutes and 43 seconds relative to historical 911 response times in the region. In the most rural region, the 90th percentile was reduced by 10 minutes and 34 seconds (Boutilier et al., 2017).

From the United States, Pulver et al. evaluated the current estimated travel times in Salt Lake County using GIS and compared it to the estimated travel times of a network of AED enabled medical drones. The Maximum Coverage Location Problem was employed to determine the best configuration of drones to increase service coverage within one minute. Several different types of data from multiple sources were used, such as 2010 Census data and OHCA in 2002 and 2003 in New York. The drone network configuration identified in this study could reach over $90 \%$ of the demand with 37 new drone stations. Due to the infeasibility in terms of the cost of these new stations, another configuration using 12 new sites and 39 existing EMS stations was identified as the most cost-efficient way to suitably reach $90 \%$ of the demand within one minute (Pulver, Wei, \& Mann, 2016). Bogle et al. assessed the access to an AED within a target time for each census block group in the state of North Carolina. A block group was considered "covered" if the expected time until arrival of an AED to its population center by either a drone or EMS was within a specified target time. The Drone Network was simulated using 0, 50, 200, 500, 
750, and 1015 Stations. 6,503 OHCAs occurred among 9.5 million North Carolinians over a 4-year drone lifespan were estimated. Compared to no network, all proposed drone networks were expected to improve survival outcomes. For example, a 500-drone network decreased the median time of defibrillator arrival from 7.7 to 2.7 minutes. Expected survival rates doubled (24.5\% versus 12.3\%), resulting in an additional 30,267 Quality-adjusted life years (QALYs) (Bogle, Rosamond, Snyder, \& Zègre-Hemsey, 2019).

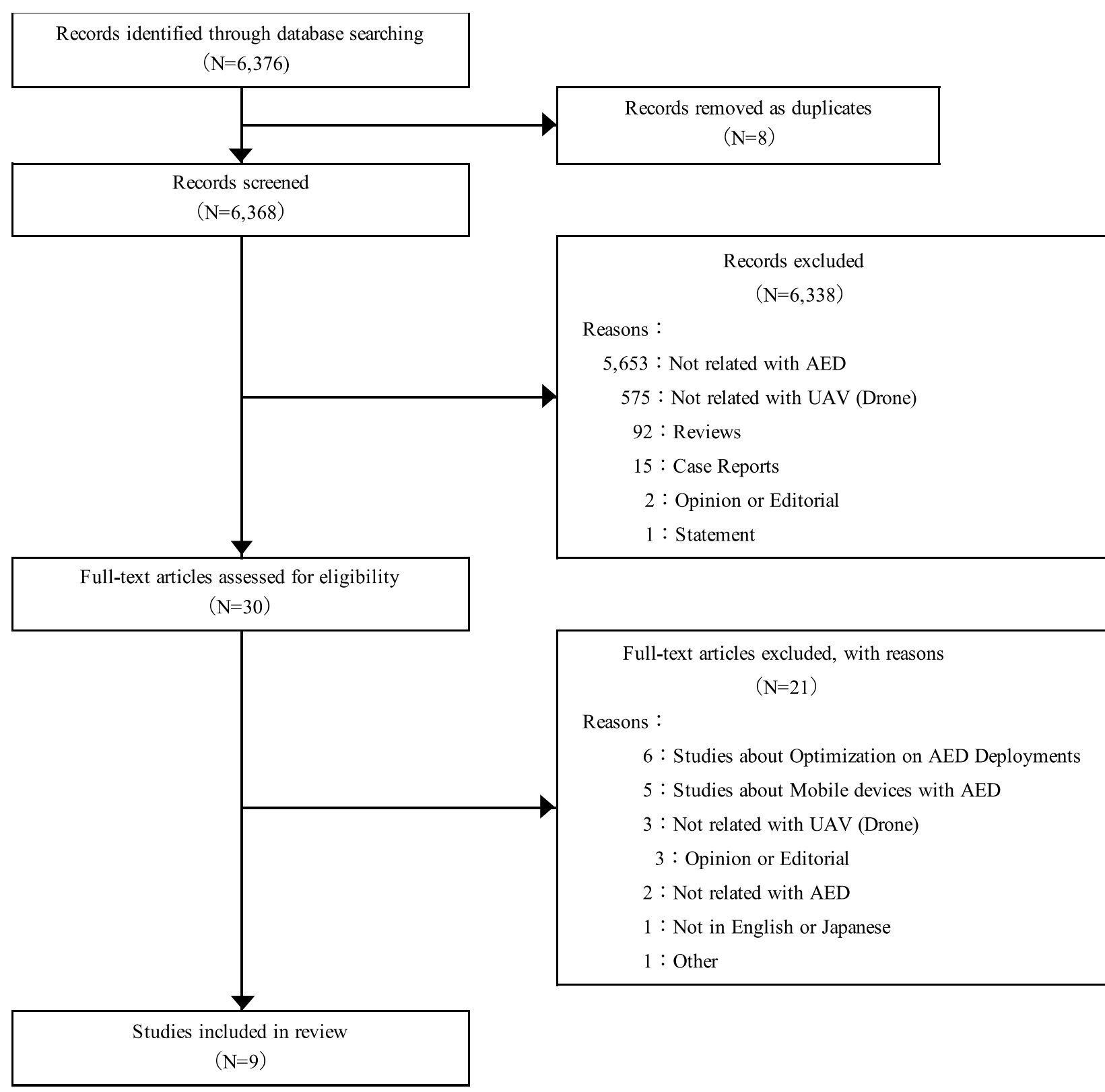

Figure 1. PRISMA flow diagram of the selection process of studies for A Systematic Review of Effectiveness of Automated External Defibrillators Delivered by Drones

\subsection{Estimated Reductions in Time to Defibrillations in OHCAs by Test Flights}

2 studies were conducted by test flights with the actual UAVs compared with EMS duration to reach to OHCA locations. Claesson et al. dispatched a drone equipped with GPS, HD Camera, autopilot software, and AED to OHCA locations occurred between 2006 and 2014 in Stockholm, Sweden, and the time differences were compared with EMS. 18 consecutive autonomous remotely operated flights were performed with a median flight distance of $3.2 \mathrm{~km}$. The drone arrived more quickly than EMS in all cases, with a median reduction in response time of 16:39 
minutes (95\% CI, 13:48-20:12; P . .001) (Claesson et al., 2017). Cheskes et al. conducted 6 series of simulation tests in 2 distinct rural communities (Town of Caledon and County of Renfrew) in Ontario, Canada. In the first 2 simulations, the drone and ambulance were dispatched from the same paramedic base. In simulations 3 and 4 , the drone and ambulance were dispatched from separate paramedic bases; and in simulations 5 and 6 , the drone was dispatched from an optimized location. No difficulties were encountered during drone activation by dispatch, ascent, landing, or bystander retrieval of the AED from the drone. During each flight, the AED drone arrived on the scene before the ambulance, between 1.8 and 8.0 minutes faster (Cheskes et al., 2020).

In addition, Claesson et al. also conducted 13 delivery test-flights on the sites from the rural area, along with his simulation study in 2016. The UAV system was tested with three scenarios: latch-release, landing on flat ground, and parachute release. The best methods of delivering the AED were found to be the use of a latch-release from low altitude (3-4 m) and landing the UAV on flat ground. In delivering the AED on site, these were both safe for bystanders and superior to parachute release (Claesson et al., 2016).

\subsection{Qualitative Analysis by Simulation Study with Interview after UAV-Delivered AED}

There are some studies not about the possible time reduction in the delivery of AED by UAV. One study was by Sanfridsson et al., who conducted an explorative simulation study. The participants in West Sweden were informed that an UAV would deliver an AED, and they were instructed to call an emergency for help to a local dispatcher and then follow the instructions that were defined in advance. Open interviews with all the participants were performed on the same day of the simulation. Those participants were split into two groups. 4 from one group were put a situation that individual bystanders had to take care of a suspected OHCA, alone. All 8 participants were afterwards put into another group, where 4 pairs of bystanders would take care of OHCA together. The interview results showed that none of the participants hesitated to retrieve the AED; instead, they experienced positive, helpful and felt relief upon AED-drone arrival and were able to retrieve and attach the AED to a manikin. (Sanfridsson et al., 2019). 
Table 2. Summary of the included studies in the review

\begin{tabular}{|c|c|c|c|c|}
\hline Article & Methods & Sample Size & Outcomes & Key Findings \\
\hline $\begin{array}{l}\text { Bogle et al. } \\
2019 \\
\text { North Carolina, } \\
\text { United States }\end{array}$ & $\begin{array}{l}\text { The access to an AED within a target time for each } \\
\text { census block group was assessed. Drone Network } \\
\text { was simulated by } 0,50,200,500,750 \text {, and } 1015 \\
\text { Stations. }\end{array}$ & $16,503 \mathrm{OHCA}$ cases & $\begin{array}{l}\text { All drone networks were expected to improve } \\
\text { survival outcomes. A 500-drone network decreased } \\
\text { the median time of defibrillator arrival from } 7.7 \text { to } \\
2.7 \text { minutes. }\end{array}$ & $\begin{array}{l}\text { Drone-delivered AED could } \\
\text { substantially improve survival } \\
\text { and neurological outcomes. }\end{array}$ \\
\hline $\begin{array}{l}\text { Boutilier et al. } \\
2017 \text { Southern } \\
\text { Ontario, } \\
\text { Canada }\end{array}$ & $\begin{array}{l}\text { A simulation model was designed to determine the } \\
\text { minimum number of drone bases and then used a } \\
\text { queuing model to determine the number of drones } \\
\text { to be stationed at each base. }\end{array}$ & $\begin{array}{l}53,702 \text { OHCA cases } \\
\text { since } 2006 \text { through } \\
2014\end{array}$ & $\begin{array}{l}\text { AED arrival time was reduced by } 6 \text { minutes and } 43 \\
\text { seconds in urban and was reduced by } 10 \text { minutes and } \\
34 \text { seconds in rural. }\end{array}$ & $\begin{array}{l}\text { Drones would improve the } \\
\text { median time to defibrillator } \\
\text { arrival. }\end{array}$ \\
\hline $\begin{array}{l}\text { Cheskes et al. } \\
2020 \text { Southern } \\
\text { Ontario, } \\
\text { Canada }\end{array}$ & $\begin{array}{l}\text { Drone and ambulance were dispatched from the } \\
\text { same paramedic base, from separate paramedic } \\
\text { bases, and from an optimized location. }\end{array}$ & $\begin{array}{l}6 \text { simulation tests in } 2 \\
\text { rural communities } \\
\text { were conducted. }\end{array}$ & $\begin{array}{l}\text { The AED drone arrived on scene before the } \\
\text { ambulance, between } 1.8 \text { and } 8.0 \text { minutes faster. }\end{array}$ & $\begin{array}{l}\text { The use of drones to deliver } \\
\text { AEDs is feasible as a response } \\
\text { to OHCA. }\end{array}$ \\
\hline $\begin{array}{l}\text { Claesson et al. } \\
2016 \\
\text { Stockholm, } \\
\text { Sweden }\end{array}$ & $\begin{array}{l}\text { This study consisted of two main subsections: } \\
\text { analysis of suitable drone placement using GIS- } \\
\text { models and delivery test-flights on these sites with } \\
\text { a UAV system with three scenarios, latch-release, } \\
\text { landing on flat ground, and parachute release. }\end{array}$ & $\begin{array}{l}20 \text { locations and } \\
3,165 \text { cases for } \\
\text { suitable drone } \\
\text { placement study and } \\
13 \text { test flights }\end{array}$ & $\begin{array}{l}\text { For urban, UAVs arrived before EMS in } 32 \% \text { of } \\
\text { cases with the mean time saved } 1.5 \text { mins, and for } \\
\text { rural, UAVs arrived before EMS in } 93 \% \text { of cases } \\
\text { with a mean amount of time saved } 19 \text { mins. The best } \\
\text { methods of delivering the AED were found to be the } \\
\text { use of a latch-release and landing. }\end{array}$ & $\begin{array}{l}\text { The suitable placement of UAV } \\
\text { systems can be designed, and } \\
\text { AED equipped UAV may } \\
\text { potentially reduce time to } \\
\text { defibrillation. The latch-release } \\
\text { technique presents low risk and } \\
\text { landing onsite is a preferable } \\
\text { alternative. }\end{array}$ \\
\hline $\begin{array}{l}\text { Claesson et al. } \\
2017 \\
\text { Stockholm, } \\
\text { Sweden }\end{array}$ & $\begin{array}{l}\text { A drone equipped with AED was dispatched to } \\
\text { OHCA locations occurred between } 2006 \text { and } 2014 \text {, } \\
\text { and the time differences were compared with EMS. }\end{array}$ & $\begin{array}{l}18 \quad \text { consecutive } \\
\text { autonomous remotely } \\
\text { operated flights }\end{array}$ & $\begin{array}{l}\text { The drone arrived more quickly than EMS in all } \\
\text { cases with a median reduction in response time of } 16 \\
\text { minutes and } 39 \text { seconds. }\end{array}$ & $\begin{array}{l}\text { It would be possible to deliver } \\
\text { an AED using a drone in } \\
\text { out-of-sight flights. }\end{array}$ \\
\hline $\begin{array}{l}\text { Kami et al. } \\
2019 \text { Japan }\end{array}$ & $\begin{array}{l}\text { AED Gripping System for AED transport UAV was } \\
\text { developed, and some test flights were designed to } \\
\text { analyze whether the gripping system could } \\
\text { maintain AED and also confirm the gripped status } \\
\text { during the flights. }\end{array}$ & $\begin{array}{l}\text { Two types of flight } \\
\text { tests were conducted. }\end{array}$ & $\begin{array}{l}\text { AED Gripping System did not drop the AED } \\
\text { accidentally and also the gripping status could be } \\
\text { confirmed during the flights. }\end{array}$ & $\begin{array}{l}\text { AED Gripping System that } \\
\text { could keep the gripped state and } \\
\text { confirm the gripping status } \\
\text { during the flights was } \\
\text { successfully developed. }\end{array}$ \\
\hline
\end{tabular}


Mackle et al. Real world datasets were combined and 2020 Northern investigated to estimate the potential improvement

Ireland, Kingdom areas.

Pulver et al. The Maximum Coverage Location Problem was employed to determine the best configuration of 2016 Salt Lake, drone network to increase service coverage within United States one minute.

2010 Census data and OHCA in 2002, and 2003 in New York
The average response time was only slightly reduced

OHCA in Belfast, the most populated trust, but the other trusts, much less populated, had been seen around a $50 \%$ improvement in response time.

Out of three options, the third configuration using 12 new sites and 39 existing EMS stations was identified as the most cost-efficient way to reach $90 \%$ of the demand within one minute.
The results show significant improvements in response time for OHCAs by drone network, especially in rural.

Sanfridsson et The participants were informed that a drone would

al. 2019

8 participants were

None of the participants hesitated to retrieve the

Drone networks show the potentiality to greatly reduce life- saving equipment travel time for OHCA victims.

West Sweden, call emergency for help. Open interviews with all

Sweden participants were performed.

split into two groups,

alone and pairs.
AED; instead they experienced it positive, helpful and felt relief upon AED-drone arrival and were able to retrieve and attach the AED to a manikin.
Retrieval of an AED as

delivered by a drone was

experienced as safe and feasible for bystanders.

Note. $\mathrm{AED}=$ Automated External Defibrillator, $\mathrm{OHCA}=$ Out of hospital cardiac arrest, GIS = Geographic Information System, UAV = Unmanned Aerial Vehicle, EMS = Emergence Medical

Services. 


\subsection{UAV Delivery Technology Study}

Another study was done by Kami et al. as a technology assessment, who developed an AED Gripping System for AED transport UAV in order to deliver quickly to remote places. This system was structured by grippers and a gripping determination system. Permanent Electromagnets as a gripper was introduced. Two types of flight experiments were conducted in Japan. The purpose of the first flight experiment was to confirm whether this gripping system could maintain the gripped state even when inertia and vibration were generated by UAV flight. Another flight experiment was conducted with the purpose of confirming whether the grip success/failure determination system could be operated properly even during flight. It was confirmed that the AED Gripping System did not drop the AED accidentally and also the gripping status could be confirmed during the flights (Kami et al., 2019).

Table 3. Publication Year

\begin{tabular}{ll}
\hline Year & N (\%) \\
\hline 2014 & $0(0.0)$ \\
2015 & $0(0.0)$ \\
2016 & $2(22.2)$ \\
2017 & $2(22.2)$ \\
2018 & $0(0.0)$ \\
2019 & $3(33.3)$ \\
2020 & $2(22.2)$ \\
\hline
\end{tabular}

\section{Discussion}

The purpose of this systematic review was to identify and appraise the currently published literatures on UAV technology with AED delivery capability. This systematic review is valuable as it should be the first attempt to find the published articles so far around this research area, UAV technology with AED delivery. The review included 9 published literature as described in Table 2, and 7 out of 9 articles analyzed the time reductions by UAV technology with AED delivery. It was a significant finding from this review that all the studies included in this review showed the potential to reduce the time to defibrillation by AED delivered by UAV.

As discussed in this introduction and also well known around the world, it is critical for OHCA patients to be defibrillated and taken care with cardiopulmonary resuscitation as early as possible so that they can survive or return to the society as healthy as possible. However, it is also a well-known issue around OHCA that AED application to the incidents is not enough in terms of the percentage of AED attempts by bystanders. Delhomme et al. described this issue, low rate of AED use, with two categories: AED deployment related issues and Bystander-related issues. AED related issues are further divided into three groups: low AED number, limited accessibility, and limited visibility. The authors also showed possible solutions to these issues, such as optimizing the AED number and locations, use of drones, and EMS dispatcher guidance to closest AEDs (Delhomme et al., 2019). Through the process during the screening of this review, there were several articles that would try to analyze or establish the optimized AED deployment. Also, there were several studies as well about new technologies, not specifically with UAV technology but others such as mobile applications, vehicle mobility, and so on. As Delhomme et al. described, UAV or drone technology would be one of the solutions to the low rate of AED usage, and again this review found the possibility to reduce the time for the defibrillation by bystanders.

Further investigation and findings are expected to support the effectiveness of UAV technology with AED delivery. This technology is so new that the evidence on the feasibility is still limited. Even from this review, most of the included studies were done by simulation models with no actual flights. At the same time, there are some flight tests that show the feasibility of the technology. One example is a demonstration experiment in Japan mentioned in the Introduction on this paper already (Tanaka, 2018). In addition, there is a pilot program conducted by Drone Delivery Canada Corporation. Phase One was already completed successfully to demonstrate that drones could deliver defibrillators faster than a traditional ambulance can. Phase Two was also conducted recently and showed a positive result by a drone dropping AED to a bystander, who can pick AED and apply to a simulated OHCA patient (DC Velocity Staff, 2020). 
In Europe, we have another example. In Sweden, there is an ongoing clinical study, titled AED-delivery Using Drones in Out-of-hospital Cardiac Arrest, sponsored by Everdrone, an emergency drone service company, with the collaboration of Sweden's emergency call center, SOS Alarm, and the Center for Resuscitation Science at Karolinska Institutet (KI). The study design is available elsewhere, registered in ClinicalTrials.gov as the number NCT04415398 (Claesson, 2020). Briefly, three drone systems are placed in designated locations to respond to emergency calls for OHCA events in the defined study area. When the drone arrives at the case location, the AED is lowered to the ground while the drone remains hovering at 30 meters altitude. The study plans to be continued by the end of September, and the results will be available later this year (Ford, 2020). These are good examples of actual flight tests in real-world settings, and it is still expected that the feasibility of this new technology should be going to be assessed more in a variety of regions and countries for actual deployment.

Moreover, this new technology might require a significant amount of financial investments in the regions that would like to be applied to. One study included in this review mentioned the financial aspects by using the QLAYs and Incremental Cost-Effectiveness Ratio (ICER) approach. Bogle et al. looked at the health economics aspect by cost-effectiveness perspective approach and demonstrated QALYs and ICERs with UAV technology for AED delivery. The authors employed a sensitivity analysis with a variety of assumptions, such as number of docking stations, willingness to apply AED to OHCA, survival rate, and so on, and it was still demonstrated that an AED drone network remained cost-effective over a wide range of assumptions (Bogle et al., 2019). This kind of sensitivity analysis around the cost-effectiveness of this new technology should be performed with different assumptions, especially in the other regions and countries to show the cost-effectiveness in the other situations as well.

There are several limitations regarding this review. As discussed in this section, UAV technology with AED delivery is one of the potential solutions to the issue of the low rate of AED usage, but this issue could be caused by the combination of several factors, such as AED locations, bystander ability, awareness of AED, and so on. The deployment of UAV technology in AED delivery should be one of the solutions, but only this approach might not be going to solve the root cause of this issue. A comprehensive approach toward the issue of low usage of AED should be considered together.

Besides, it must be noted that UAV flights are still limited by regulations in many countries and regions. For example, in Japan, there are some laws under the Civil Aeronautics Act to regulate UAV flights. There are mainly three areas or categories that prohibit us from operating UAV, such as areas around airports, airspace higher than 150 meters, and areas categorized as high population density. There are additional restrictions on UAV flights such as night flight, out of visual contact, transportation of explosive or hazardous materials, and so on (Terada, 2018). These prohibitions and restrictions can be cleared by the permission or approval from Japan Minister of Land, Infrastructure, Transportation and Tourism, but in considering AED delivery by UAV, these have to be taken into account not as individual cases but comprehensively.

\section{Conclusion}

This systematic review was designed and conducted to explore the literatures which showed the potential effectiveness of the implementation of UAV technology in AED delivery method, especially the reduction of the time to defibrillation in OHCA cases which would result in the early intervention of these events. This review process finally included 9 studies mainly from Western countries such as the United Kingdom, Sweden, Canada, the United States, and Japan. Seven studies demonstrated the potential reductions in the delivery of the defibrillation in OHCAs by using simulated methods and/or test flights by UAV. More studies are expected to show the effectiveness of the deployment of this new technology, especially around the feasibility in the real-world setting by the actual flights and the cost-effectiveness analysis of how UAV should be introduced, such as the area (rural or urban), number of bases, number of drones, and other factors.

\section{Acknowledgements}

This study was conducted under the supervision of Professor Takao Tashiro at Open University of Japan, for Human Life and Health Sciences under Ph. D. Program of the School of Graduated Studies. The study design was first presented during the 13th Seminar to Nurture Young Researchers hosted by Japan Health Economics Association. The chair was Dr. Noriko Sasaki from Kyoto University, and the commentator was Dr. Rei Goto from Keio Business School. Dr. Goto made valuable feedback from a variety of perspectives. Professor Shigeru Tanaka from Keio University hosted a seminar camp, which gave another opportunity for me to present the study design in front of the participants. Finally, my family members put great support on my efforts for this study to be completed. 


\section{Competing Interests Statement}

The author of this study is an employee of Philips Japan.

\section{References}

American Heart Association. (2000). ECC Guidelines Part 4: The Automated External Defibrillator - Key Link in the Chain of Survival. Circulation, 102(suppl_1), I-60-I-76. https://doi.org/10.1161/circ.102.suppl_1.I-60

Bogle, B. M., Rosamond, W. D., Snyder, K. T., \& Zègre-Hemsey, J. K. (2019). The Case for Drone-assisted Emergency Response to Cardiac Arrest: An Optimized Statewide Deployment Approach. North Carolina Medical Journal, 80(4), 204-212. https://doi.org/10.18043/ncm.80.4.204

Boutilier, J. J., Brooks, S. C., Janmohamed, A., Byers, A., Buick, J. E., Zhan, C., ... Rescu Epistry Investigators. (2017). Optimizing a Drone Network to Deliver Automated External Defibrillators. Circulation, 135(25), 2454-2465. https://doi.org/10.1161/CIRCULATIONAHA.116.026318

Cheskes, S., McLeod, S. L., Nolan, M., Snobelen, P., Vaillancourt, C., Brooks, S. C., ... Drennan, I. R. (2020). Improving Access to Automated External Defibrillators in Rural and Remote Settings: A Drone Delivery Feasibility Study. Journal of the American Heart Association, e016687. https://doi.org/10.1161/JAHA.120.016687

Claesson, A. (2020). AED-delivery Using Drones in Out-of-hospital Cardiac Arrest. Retrieved August 29, 2020, from ClinicalTrials.gov website: https://clinicaltrials.gov/ct2/show/NCT04415398

Claesson, A., Bäckman, A., Ringh, M., Svensson, L., Nordberg, P., Djärv, T., \& Hollenberg, J. (2017). Time to Delivery of an Automated External Defibrillator Using a Drone for Simulated Out-of-Hospital Cardiac Arrests vs Emergency Medical Services. JAMA, 317(22), 2332. https://doi.org/10.1001/jama.2017.3957

Claesson, A., Fredman, D., Svensson, L., Ringh, M., Hollenberg, J., Nordberg, P., ... Ban, Y. (2016). Unmanned aerial vehicles (drones) in out-of-hospital-cardiac-arrest. Scandinavian Journal of Trauma, Resuscitation and Emergency Medicine, 24. https://doi.org/10.1186/S13049-016-0313-5

DC Velocity Staff. (2020, August). Drone proves faster than a speeding ambulance in field tests. DC Velocity. Retrieved from https://www.dcvelocity.com/articles/46837-drone-proves-faster-than-a-speeding-ambulance-in-field-tests

Delhomme, C., Njeim, M., Varlet, E., Pechmajou, L., Benameur, N., Cassan, P., ... Karam, N. (2019). Automated external defibrillator use inout-of-hospital cardiac arrest: Current limitations and solutions. Archives of Cardiovascular Disease, 112, 217-222. https://doi.org/https://doi.org/10.1016/j.acvd.2018.11.001

Fire and Disaster Management Agency. (2019). Fire White Papers. Retrieved July 19, 2020, from https://www.fdma.go.jp/publication/hakusho/r1/47787.html

Ford, P. (2020, May 19). Drones join emergency care front line in Sweden with defibrillator drops. MobiHealthNews. Retrieved from https://www.mobihealthnews.com/news/europe/drones-join-emergency-care-front-line-sweden-defibrillator -drops

Grieco, L. (2015). Alec Momont's Ambulance Drone seizes voters' hearts to win the Frame Public Award - News Frameweb. Retrieved July 18, 2020, from Frame Publishers website: https://www.frameweb.com/news/alec-momont-s-ambulance-drone-seizes-voters-hearts-to-win-the-frame-p ublic-award

Kami, T., Harata, Y., Yamaguchi, T., Okada, Y., Ohno, K., \& Tadokoro, S. (2019). No-power Gripping using Permanent Electromagnet for AED Transport UAV and Determination of Gripping Success by Measurement of Counter Electromotive Force. Journal of the Robotics Society of Japan, 37(8).

Mackle, C., Bond, R., Torney, H., Mcbride, R., Mclaughlin, J., Finlay, D., ... Mceneaney, D. (2020). A Data-Driven Simulator for the Strategic Positioning of Aerial Ambulance Drones Reaching Out-of-Hospital Cardiac Arrests: A Genetic Algorithmic Approach. IEEE Journal of Translational Engineering in Health and Medicine, 8, 1900410. https://doi.org/10.1109/JTEHM.2020.2987008

Moher, D., Liberati, A., Tetzlaff, J., Altman, D. G., \& Group, T. P. (2009). Preferred Reporting Items for Systematic Reviews and Meta-Analyses: The PRISMA Statement. PLoS Medicine, 6(7), e1000097. https://doi.org/10.1371/journal.pmed.1000097

National Institute for Health Research. (n.d.). PROSPERO. Retrieved April 1, 2020, from 
https://www.crd.york.ac.uk/prospero/

National Institute of Informatics. (2018). CiNii. Retrieved from https://ci.nii.ac.jp/

Pulver, A., Wei, R., \& Mann, C. (2016). Locating AED Enabled Medical Drones to Enhance Cardiac Arrest $\begin{array}{llllll}\text { Response Times. } & \text { Prehospital Emergency }\end{array}$ https://doi.org/10.3109/10903127.2015.1115932

Ramachandra, K. (2016). Drones in healthcare: a global and national perspective. The 7th International Conference on Transforming Healthcare with Information Technology, and The 21 Conference of the International Society for Telemedicine and EHealth Chennai , India, (October), 1-28.

Sanfridsson, J., Sparrevik, J., Hollenberg, J., Nordberg, P., Djärv, T., Ringh, M., .. Claesson, A. (2019). Drone delivery of an automated external defibrillator - a mixed method simulation study of bystander experience. Scandinavian Journal of Trauma, Resuscitation and Emergency Medicine, 27(1), 40. https://doi.org/10.1186/s13049-019-0622-6

Shirane, T. (2020). A Systematic Review of Effectiveness of Automated External Defibrillators (AED) delivered by Unmanned Aerial Vehicles (UAV). Retrieved July 12, 2020, from Prospero website: https://www.crd.york.ac.uk/prospero/display_record.php?ID=CRD42020167599

Tanaka, M. (2018, March 14). AED Delivery by Drone, First Large Scale Demonstration Experiment in Japan. The Sankei News. Retrieved from https://www.sankei.com/life/news/180314/lif1803140009-n1.html

Terada, M. (2018). Drone and Legal Restraints. Retrieved from http://www.kokusen.go.jp/wko/pdf/wko-201801_05.pdf

\section{Copyrights}

Copyright for this article is retained by the author(s), with first publication rights granted to the journal.

This is an open-access article distributed under the terms and conditions of the Creative Commons Attribution license (http://creativecommons.org/licenses/by/4.0/). 